\title{
BMJ Open Nationwide population-based cohort study of uterine rupture in Belgium: results from the Belgian Obstetric Surveillance System
}

\author{
G Vandenberghe, ${ }^{1} \mathrm{M}$ De Blaere, ${ }^{1} \mathrm{~V}$ Van Leeuw,${ }^{2} \mathrm{~K}$ Roelens, ${ }^{1} \mathrm{Y}$ Englert, ${ }^{3}$ \\ M Hanssens, ${ }^{4} \mathrm{H}$ Verstraelen ${ }^{1}$
}

To cite: Vandenberghe G, De Blaere M, Van Leeuw V, et al. Nationwide population-based cohort study of uterine rupture in Belgium: results from the Belgian Obstetric Surveillance System. BMJ Open 2016;6:e010415. doi:10.1136/bmjopen-2015010415

- Prepublication history and additional material is available. To view please visit the journal (http://dx.doi.org/ 10.1136/bmjopen-2015010415).

Received 4 November 2015 Revised 26 February 2016 Accepted 1 March 2016

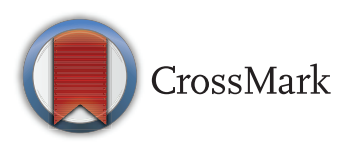

${ }^{1}$ Department of Obstetrics \& Gynaecology, Ghent University Hospital, Ghent, Belgium

${ }^{2}$ Centre d'Epidémiologie Périnatale (CEpiP), Bruxelles, Belgium

${ }^{3}$ Faculty of Medicine, Centre d'Epidémiologie Périnatale (CEpiP), Research Laboratory on Human Reproduction, Université Libre de Bruxelles (ULB), Brussels, Belgium ${ }^{4}$ Department of Obstetrics \& Gynaecology, University Hospital Leuven, Leuven, Belgium

Correspondence to G Vandenberghe; griet.vandenberghe@uzgent. be

\section{ABSTRACT}

Objectives: We aimed to assess the prevalence of uterine rupture in Belgium and to evaluate risk factors, management and outcomes for mother and child.

Design: Nationwide population-based prospective cohort study.

Setting: Emergency obstetric care. Participation of $97 \%$ of maternity units covering $98.6 \%$ of the deliveries in Belgium.

Participants: All women with uterine rupture in Belgium between January 2012 and December 2013. 8 women were excluded because data collection forms were not returned.

Results: Data on 90 cases of confirmed uterine rupture were obtained, of which 73 had a previous Caesarean section (CS), representing an estimated prevalence of $3.6(95 \% \mathrm{Cl} 2.9$ to 4.4$)$ per 10000 deliveries overall and of 27 (95\% Cl 21 to 33$)$ and 0.7 (95\% Cl 0.4 to 1.2) per 10000 deliveries in women with and without previous CS, respectively. Rupture occurred during trial of labour after caesarean section (TOLAC) in 57 women $(81.4 \%, 95 \% \mathrm{Cl} 68 \%$ to $88 \%)$, with a high rate of augmented $(38.5 \%)$ and induced $(29.8 \%)$ labour. All patients who underwent induction of labour had an unfavourable cervix at start of induction (Bishop Score $\leq 7$ in 100\%). Other uterine surgery was reported in the history of 22 cases (24\%, 95\% Cl $17 \%$ to $34 \%$ ), including 1 case of myomectomy, 3 cases of salpingectomy and 2 cases of hysteroscopic resection of a uterine septum. 14 cases ruptured in the absence of labour (15.6\%, $95 \% \mathrm{Cl} 9.5 \%$ to $24.7 \%)$. No mothers died; 8 required hysterectomy $(8.9 \%, 95 \% \mathrm{Cl} 4.6 \%$ to $16.6 \%$ ). There were 10 perinatal deaths (perinatal mortality rate $117 / 1000$ births, $95 \% \mathrm{Cl} 60$ to 203) and perinatal asphyxia was observed in 29 infants (34.5\%, $95 \% \mathrm{Cl} 25.2 \%$ to $45.1 \%$ ).

Conclusions: The prevalence of uterine rupture in Belgium is similar to that in other Western countries. There is scope for improvement through the implementation of nationally adopted guidelines on TOLAC, to prevent use of unsafe procedures, and thereby reduce avoidable morbidity and mortality.

\section{BACKGROUND}

Uterine rupture is a rare, but potentially devastating complication of pregnancy, whereby

\section{Strengths and limitations of this study}

- This is a nation-wide study of Belgian maternities, with excellent participation and response rates $(98.8 \%)$

- The cases were collected on a monthly basis using the standard methodology of the Obstetric Surveillance Systems.

- Data from the background population as control group were limited to those available in the Belgian perinatal registry.

- The study lacks a reliable control for under-reporting.

the uterine wall tears during pregnancy or delivery, extending to the uterine serosa and occasionally involving the bladder or broad ligament. ${ }^{2}$ The course is usually milder in case of a uterine dehiscence, when rupture is confined to the uterine muscle without affecting the uterine serosa. ${ }^{12}$

Disruption of the uterine wall can be accompanied by displacement of the baby into the abdomen, causing severe asphyxia and perinatal death, and by massive maternal bleeding necessitating massive transfusion or hysterectomy to save the mother's life.

Albeit a rare event, complicating an estimated $0.03 \%$ of pregnancies in developed countries, ${ }^{3}$ the severity of this complication has a profound impact on obstetrical practice.

Large population-based studies in European countries, including obstetric surveillance systems, ${ }^{4} 5$ have improved our knowledge of risk factors and management of uterine rupture, and have guided strategies for prevention. ${ }^{6-10}$ In developed countries, uterine rupture most commonly occurs in uteri scarred by previous caesarean section (CS), mainly at term and during labour, and is even more frequent when labour is induced or augmented. Awareness of this risk has contributed to a more 
cautious policy towards trial of labour after caesarean section (TOLAC), stated in widely used guidelines. ${ }^{1} 1112$

Belgium has a large number of tertiary referral centres providing neonatal intensive care $(n=19)$ along with a high concentration of small-volume maternity units. ${ }^{13}$ Obstetric care is mainly organised in private practice. The impact of this almost exclusively specialist-led care, the high rate of induction of labour ${ }^{13}$ $(26.5 \% \text { in } 2013)^{14-16}$ and the steadily increasing CS rate $\left(20.7 \%\right.$ in $\left.2013^{14-16}\right)$ on the prevalence of uterine rupture in Belgium is currently not known.

We aimed to investigate the prevalence of uterine rupture in Belgium and to assess risk factors, management and outcomes, for mother and child.

\section{METHODS}

Belgian Obstetric Surveillance System (B.OSS)

Uterine rupture in Belgium has been registered as part of a national reporting system to study rare obstetric complications, being the first completed study of this newly developed project. The B.OSS was constituted in 2011 and initiated registration in January 2012, with support of the College for Mother and Newborn, a consultative body of the Federal Public Service of Health in Belgium.

\section{Case reporting}

B.OSS has adopted the methodology for case reporting of severe obstetric morbidity developed by the UK Obstetric Surveillance System (UKOSS), ${ }^{4}$ pioneer of the obstetric surveillance systems united in the International Network of Obstetric Survey Systems (INOSS). ${ }^{5}$ Participation of $97 \%$ of Belgian maternity units $(n=113)$ was obtained, covering 98.6\% (248 681) of deliveries in the study period. Briefly, an appointed contact person (obstetrician $(\mathrm{OB})$ /gynaecologist or senior-midwife) in each participating maternity unit $(n=110)$ was invited by monthly mailing to report a selected number of rare obstetric complications (including uterine rupture, as well as eclampsia and peripartum hysterectomy, and/ or embolisation for massive obstetric haemorrhage) that had occurred in the preceding month. In the event a case was reported in reply, the contact person was asked to complete an extensive data collection form. Confidentiality was guaranteed for mother, provider and hospital; person-identifiable information was eliminated from data-analysis. In case of incomplete reporting, the appointed contact person was encouraged repeatedly by email and phone to provide missing data, up to 6 months following the period of case reporting.

\section{Data collection, processing and cleaning}

Initially, data on reported cases were obtained through use of a standardised form, filled out electronically or on hard copy, according to preference. Web-based datacollection was gradually introduced following the launch of the B.OSS website (http://www.b-oss.be) in August 2013, facilitating monthly reporting and completion of data collection forms online. Standardised forms were entered manually into the website forms by two investigators, independently, to assure quality of data entry. Collected data of completed online data collection forms were coded and exported as a comma-separated values file.

\section{Registered variables}

Data collection forms requested information on maternal characteristics, medical history and obstetrical history, details on the index pregnancy, circumstances of the event, and the management and outcome for mother and neonate.

\section{Case definition}

B.OSS aimed to collect all cases of uterine rupture in Belgium at any gestational age corresponding to an anatomical definition (delineated by $\mathrm{UKOSS}^{7}$ ) or to a clinical definition (delineated by the LEMMoN study in the Netherlands ${ }^{8}$ ), allowing for the comparison of Belgian data with both population-based studies. Uterine rupture as defined by UKOSS is 'a complete separation of the wall of the pregnant uterus, with or without expulsion of the fetus, involving rupture of the membranes at the site of the uterine rupture or extension into uterine muscle separate from any previous scar, and endangering the life of the mother or the fetus'. Uterine rupture as defined by the LEMMoN study is 'the occurrence of clinical symptoms leading to an emergency $\mathrm{CS}$, at which the presumed diagnosis of uterine rupture was confirmed; or a peripartum hysterectomy or laparotomy is required for uterine rupture after a vaginal birth'.

Anatomical details were requested in the data collection forms, defining the status of the myometrium, the peritoneum and the fetal membranes. This anatomical distinction enables the identification of cases that correspond to the UKOSS definition and the comparison with other population-based studies that have used anatomical definitions in the same manner. B.OSS has specifically excluded cases of asymptomatic dehiscence (intact uterine peritoneum) noted incidentally at CS, in accordance with $\mathrm{UKOSS}^{7}$ and LEMMoN. ${ }^{8}$

\section{Study period}

B.OSS aimed to collect all cases of uterine rupture occurring in Belgium from January 2012 to December 2013.

\section{Missing data}

Eight reported cases were excluded from the present analysis, because data collection forms were not returned. Data collection forms that were returned were not always complete for all variables. Study data were evaluated by the number of cases missing per variable 
and by the number of variables missing per case. No further cases were excluded because of missing data.

\section{Statistical analysis}

The most recently available data from the Belgian perinatal registry were used as denominator or control group to calculate rates of prevalence and relative risks. The Belgian perinatal registry (Studiecentrum voor Perinatale Epidemiologie (SPE) in Flanders, ${ }^{14}$ Centre d'Epidémiologie Périnatale (CEpiP) in Brussels ${ }^{15}$ and Wallonia ${ }^{16}$ ) collects data on a mandatory basis, covering nearly $100 \%$ of births in Belgian maternity units and homebirths. A selected set of perinatal data are recorded by the $\mathrm{OB}$, midwife and neonatologist immediately after a birth. According to Belgian legislation, births are registered as such, in case of a live birth or stillbirth at or after 22 completed weeks of gestation or, if gestational age is missing, at a birth weight of $500 \mathrm{~g}$ or more.

The overall prevalence of uterine rupture was calculated using the total number of mothers who had given birth in Belgium in 2012-2013, as denominator, corrected for three hospitals that did not participate in B.OSS. The number of mothers with previous CS, in 2012-2013, was used as denominator to calculate the prevalence of uterine rupture in women with and without previous CS. Belgium has a high rate of induction of labour, but data of method or medication used for induction are not available. Sociodemographic and obstetric risk factors were obtained from SPE ${ }^{14}$ and CEpiP (2012-2013) ${ }^{15}{ }^{16}$; data on marital status and employment were only available from CEpiP.

Neonatal asphyxia was defined as Apgar score $<7$ at $5 \mathrm{~min}$ and/or the umbilical artery $\mathrm{pH} \leq 7.0$, and/or need for resuscitation including endotracheal ventilation, and/or neurological manifestations (seizures), and/or whole body hypothermia treatment initiated after birth. ${ }^{17}$ Relative risks and 95\% CIs were calculated in univariate analyses, comparing frequencies of events between the study group and control group, with ordinary Pearson's $\chi^{2}$ tests using weighted cases when appropriate. $p$ Values of $<0.05$ were considered statistically significant. Data were analysed using the statistical software package IBM SPSS statistics V.22.0 (IBM Corp, IBM SPSS Statistics for Windows, Version 22.0, Armonk, New York, USA: IBM Corp, 2013).

\section{RESULTS}

\section{Prevalence}

From January 2012 to December 2013, 90 confirmed cases of uterine rupture were documented. Eight more reported cases needed to be excluded because of lacking data collection forms. The corresponding prevalence of uterine rupture in Belgium is therefore estimated at 3.6 (95\% CI 2.9 to 4.4) per 10000 deliveries. When taking into account only cases of complete rupture $(\mathrm{n}=74)$, the estimated prevalence is 2.9 (2.3 to 3.7). Details on reported cases and completeness of data collection forms are shown in figure 1 .

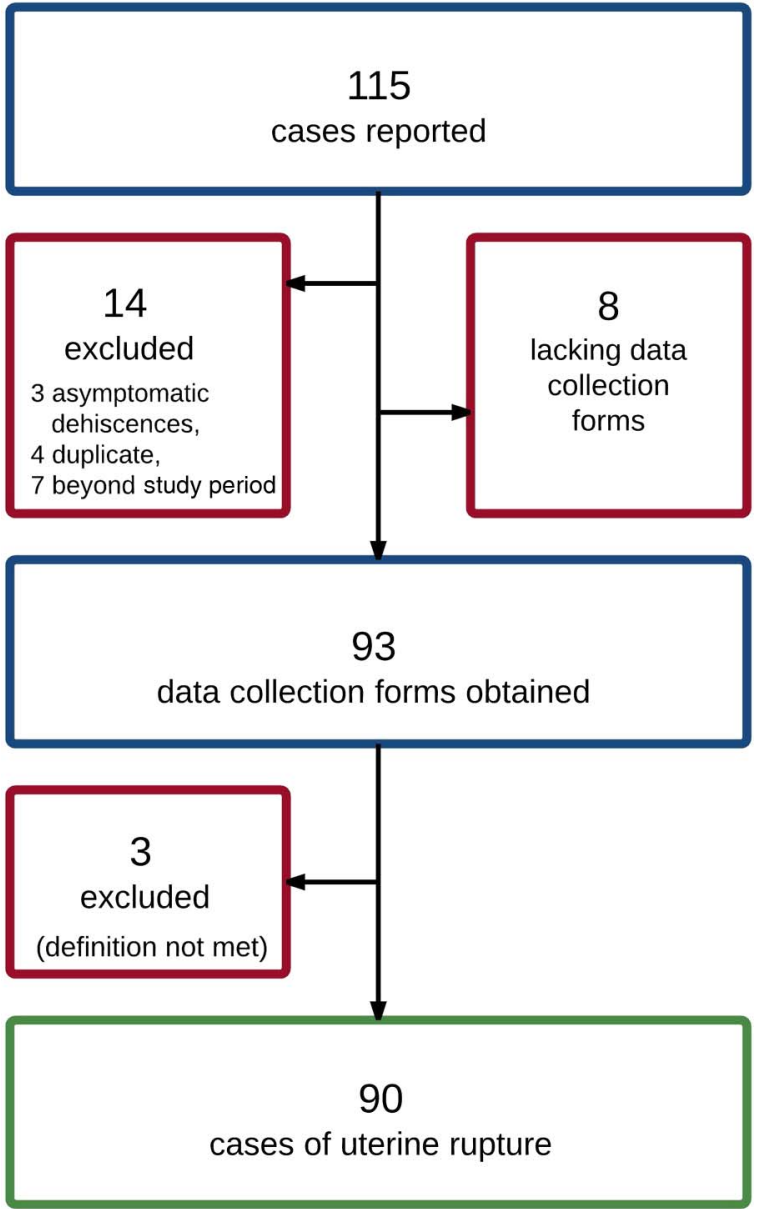

Figure 1 Flowchart of case reporting and data collection.

\section{Risk factors}

Women's characteristics

Relevant sociodemographic, medical and obstetrical characteristics are displayed in table 1, in comparison with national data when available. Of note, patients with uterine rupture included six cases (7.7\%) with documented uterine anomaly, of whom two had a septal resection prior to the index pregnancy, and one case of uterine rupture in a patient with osteogenesis imperfecta type 1. Rupture in the latter patient, who had undergone a previous CS, occurred during the latent phase of labour at term (38 weeks) and involved a longitudinal tear towards the fundus.

\section{Obstetrical risk factors}

\section{Previous CS and miscellaneous uterine surgery}

Seventy-three cases of uterine rupture $(81.1 \%)$ occurred in women who had at least one previous CS, representing an estimated prevalence of 27 (95\% CI 21 to 33) per 10000 deliveries in women with previous CS. Seventeen cases of uterine rupture $(18.8 \%)$ were observed in women who did not have a previous CS, representing an estimated prevalence of 0.7 (95\% CI 0.4 to 1.2) per 10000 deliveries in women without previous CS. Eight 
Table 1 Relevant sociodemographic, medical and obstetrical risk factors in cases of uterine rupture

\begin{tabular}{|c|c|c|c|c|}
\hline & $\begin{array}{l}\text { Cases of uterine rupture } \\
2012-2013(n=90)^{\star} \\
n, \%\end{array}$ & $\begin{array}{l}\text { Background } \\
\text { population } \\
2012-2013 \\
(n=252272) \\
n, \%\end{array}$ & $\begin{array}{l}\text { Unadjusted RR } \\
(95 \% \mathrm{Cl})\end{array}$ & p Value \\
\hline \multicolumn{5}{|l|}{ Sociodemographic factors } \\
\hline Maternal age $\geq 35$ years & $17(18.8)$ & 43256 (17) & $1.11(0.72$ to 1.70$)$ & 0.6 \\
\hline BMl at booking $\geq 30 \mathrm{~kg} / \mathrm{m}^{2}$ & $13(19.6)$ & $29453(12)$ & 1.59 (0.9 to 2.59$)$ & 0.05 \\
\hline Ethnicity non-white $†$ & $5(5.5)$ & - & - & - \\
\hline Neither married nor cohabiting & $3(3.8)$ & 20785 (17) & $0.22(0.07$ to 0.69$)$ & 0.008 \\
\hline Unemployed & $22(24.4)$ & $51296(43)$ & 0.72 (0.50 to 1.02$)$ & 0.06 \\
\hline Smoking & $8(8.8)$ & - & - & - \\
\hline \multicolumn{5}{|l|}{ Medical factors } \\
\hline $\begin{array}{l}\text { Uterine anomaly (bicornuate, } \\
\text { septate) }\end{array}$ & $6(6.6)$ & - & - & - \\
\hline Connective tissue disease $\neq$ & $1(1.1)$ & - & - & - \\
\hline \multicolumn{5}{|l|}{ Obstetrical factors } \\
\hline Parity $\geq 3$ & $9(10)$ & $18855(7.4)$ & $1.33(0.71$ to 2.48$)$ & 0.3 \\
\hline Nulliparity & $6(6.6)$ & 110711 (43.9) & 0.15 (0.07 to 0.32$)$ & $<0.0001$ \\
\hline Induction of labour & $24(27.9)$ & 68703 (26.7) & $1.03(0.7$ to 1.4$)$ & 0.8 \\
\hline Previous CS & $73(81.1)$ & 27007 (10.7) & 7.57 (6.85 to 8.37$)$ & $<0.0001$ \\
\hline $\begin{array}{l}\text { Previous CS, cases <24 weeks } \\
\text { excluded }\end{array}$ & $70(81.3)$ & & & \\
\hline Trial of labour after CS & $57 / 70(81.4)$ & $12754 / 27007$ (47.2) & 1.39 (1.15 to 1.69$)$ & $<0.001$ \\
\hline $\begin{array}{l}\text { Interpregnancy interval } \\
\leq 12 \text { months }\end{array}$ & $12(16.4)$ & - & - & - \\
\hline $\begin{array}{l}\text { Artificial reproductive technology } \\
\text { (IVF/ICSI) }\end{array}$ & $4(4.4)$ & $9233(3.7)$ & $1.21(0.46$ to 3.15$)$ & 0.6 \\
\hline $\begin{array}{l}\text { Abnormal placentation (accreta, } \\
\text { increta, percreta) }\end{array}$ & $1(1.1)$ & - & - & - \\
\hline Birth weight $\geq 4000 \mathrm{~g}$ & $11(12.2)$ & $19967(7.8)$ & 1.67 (0.96 to 2.90$)$ & 0.06 \\
\hline Breech presentation & $4(4.4)$ & $12630(4.9)$ & 0.93 (0.35 to 2.42) & 0.8 \\
\hline \multicolumn{5}{|c|}{$\begin{array}{l}\text { *Study data were not complete for all variables; data available on BMI }(n=66) \text {, marital status }(n=77) \text {, employment }(n=71) \text {, smoking }(n=87) \text {, } \\
\text { ART ( } n=89) \text {, birth weight ( } n=84) \text {, interpregnancy interval }(n=67) \text {. } \\
\text { +White ethnicity defined as European, Middle-Eastern, North-African, white South-African. Five women were of African descent defined as } \\
\text { African, Caribbean or Afro-American ethnicity. } \\
\text { fConnective tissue disease: the study included one known case of osteogenesis imperfecta type I. } \\
\text { ART, artificial reproductive technology; BMI, body mass index; CS, Caesarean section; CTG, cardiotocography; ICSI, intracytoplasmic sperm } \\
\text { injection; IVF, in vitro fertilisation; RR, relative risk. }\end{array}$} \\
\hline
\end{tabular}

women without a previous CS $(8 / 17)$ had one or more other types of uterine surgery documented in their history (dilation and curettage (D\&C) $(n=5)$, salpingectomy $(n=2)$, resection of uterine septum $(n=2)$, myomectomy $(n=1)$, manual removal of the placenta $(n=1))$. In none of these cases was uterine perforation confirmed. Similarly, 14 women with previous CS also had a history of another type of uterine surgery (D\&C $(n=12)$, manual removal of placenta $(n=1)$, salpingectomy for an interstitial pregnancy $(n=1))$; with documented uterine perforation in the latter case followed by suturing of the uterine cornua. Interestingly, this rupture occurred at the site of the cornual scar. Finally, nine women did not have any surgical risk factor that could explain a weakness in the uterine wall (see online supplementary figure $\mathrm{S} 1$ ).

In the cases with previous CS, the interpregnancy interval was beyond 24 months in $58 \%$ of the cases, 1223 months in $24 \%$ of cases and $<12$ months in 12 cases
(18\%), of whom four became pregnant within the first 6 months after previous CS.

\section{Labour and use of uterotonic drugs}

Four cases of uterine rupture occurred before 24 completed weeks of gestation. In one patient, uterine rupture occurred during termination of pregnancy at 18 weeks, by means of prostaglandins, in a patient with two previous CS. The second patient received prostaglandins because of intrauterine fetal death (IUFD) at an estimated 22 weeks in an unrecognised pregnancy; this patient had undergone four previous CS. The third case was a rupture at 18 weeks in a previously unrevealed bicornuate uterus. The fourth case was a fundal rupture at 18 weeks at the site of a placenta percreta. This patient had two previous CS and two D\&C's for termination of pregnancy and was managed by a hysterectomy. These four cases were excluded from analysis of neonatal outcome. 
Table 2 Signs and symptoms, and combinations of symptoms prior to diagnosis of uterine rupture

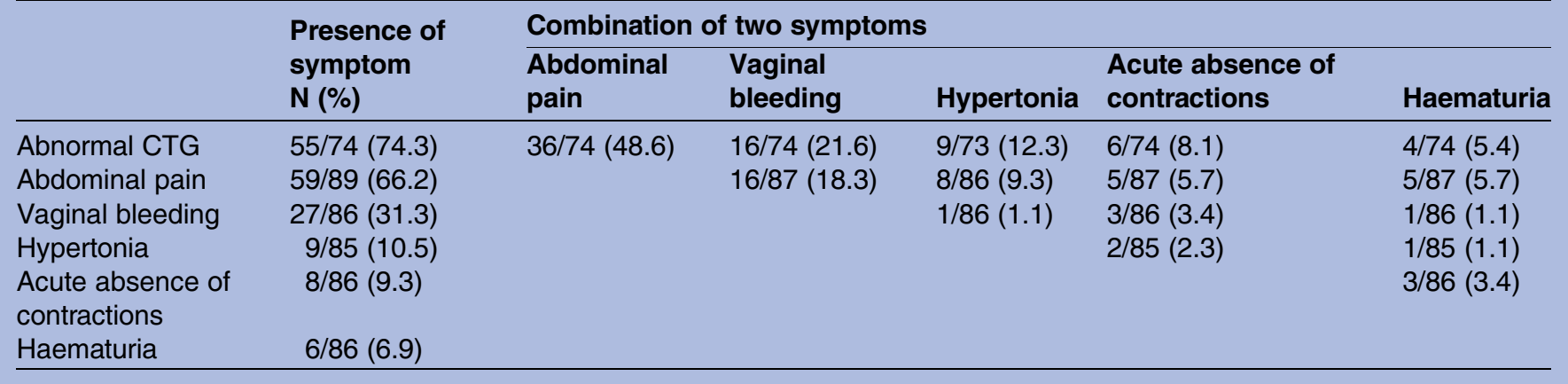

The median gestational age of the 86 remaining cases was 39 weeks (range $25-41$ weeks).

In 71 cases $(82.5 \%)$, uterine rupture occurred during labour. Of these, labour was induced in 22 cases $(25.5 \%)$ and augmented by use of oxytocin in 24 cases (28\%) while another 24 cases laboured spontaneously without the use of uterotonic drugs (28\%). Sixteen cases were stated to have ruptured in the absence of labour $(18.6 \%)$, two of these women having received vaginal prostaglandins in an attempt to induce labour (see online supplementary figure S2).

The rate of TOLAC in this study was $81.4 \%(n=57)$, including in 17 women where it was induced $(29.8 \%)$ and in 22 where it was augmented (38.5\%). The Bishop score prior to induction, as the most commonly used predictor for the readiness of the cervix for induction, ${ }^{18}$ was unfavourable in the majority of these women $(<6$ in $82 \%, \leq 7$ in $100 \%)$.

\section{Presentation of the uterine rupture}

Signs and symptoms that raised suspicion of uterine rupture are demonstrated in table 2 . In five cases, there were signs of maternal shock (hypotension, sweating, pallor, maternal collapse); shoulder pain was mentioned in one case.

In 19 cases $(21.1 \%)$, the diagnosis was made after vaginal delivery, with vaginal bleeding occurring as the presenting sign in $47 \%$ of the cases. Delivery was assisted with vacuum $(n=10)$ or forceps $(n=2)$ because of fetal distress $(n=7)$ or maternal reasons $(n=5)$. One case of uterine rupture was detected during routine manual examination of the uterus postdelivery, an obsolete procedure that is still practised by a minority of OBs.

\section{Management of uterine rupture and outcome of mother and child}

Emergency CS was performed in 67 women (74\%). Dilation at the moment of decision was $0-3 \mathrm{~cm}$ in nearly half of these women $(n=32)$, while nine women $(13 \%)$ were fully dilated.

Eight women underwent a hysterectomy (9\%) (see online supplementary figure S3). Reported reason to perform the hysterectomy was massive haemorrhage in four cases while the other four cases underwent hysterectomy mainly because of major anatomical damage to the uterus.

Location of the uterine rupture was in the lower uterine segment in the majority of cases $(n=57,63 \%)$. Other reported locations of rupture were fundal $(n=13$, $14 \%)$, longitudinal $(n=12,13 \%)$, high transverse $(n=4$, $4 \%)$ and cornual $(n=2,2 \%)$. The bladder or the parametrium was involved in $7(8 \%)$ and in 12 women $(13 \%)$, respectively.

Twenty women $(22.2 \%)$ were admitted to an intensive care unit (ICU), with a mean stay of 2.1 (1-7) days. Three women required intubation and ventilation, one patient suffered from aspiration pneumonia. Thirty-six women received transfusion $(40 \%), 14$ women were transfused with $>4$ units of packed cells (PC) and fresh frozen plasma (FFP). Other reported maternal morbidity included a vesicovaginal fistula $(\mathrm{n}=1)$, a nephrostomy $(n=1)$ and an abcedation $(n=1)$.

The neonatal outcome is demonstrated in the flowchart in figure 2. There were 10 perinatal deaths in consequence of the uterine rupture: two neonates died during rupture before birth and eight neonates died in the first 7 days of life. Early neonatal deaths occurred at

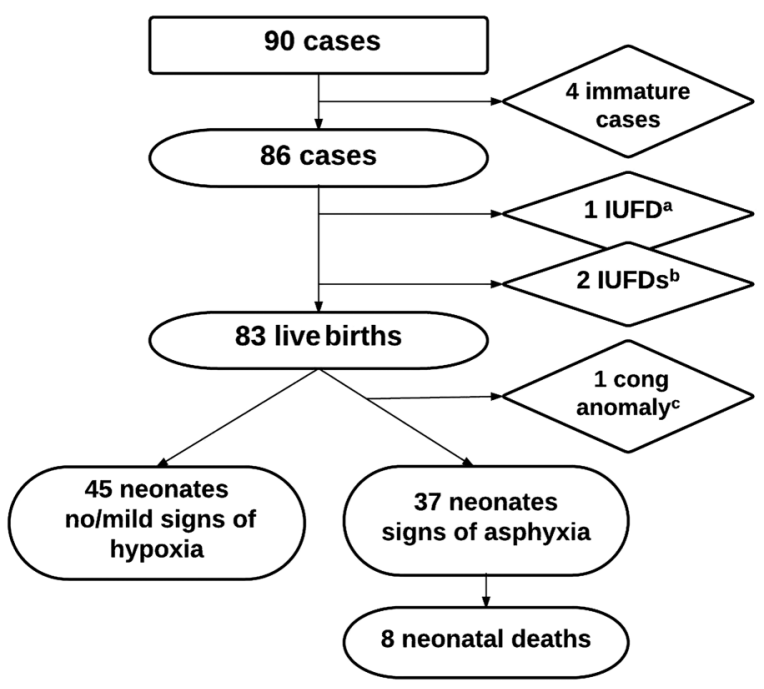

Figure 2 Neonatal outcome in 90 cases of uterine rupture. Cong, congenital; IUFD, intrauterine fetal death. 
a term gestational age $\left(>39^{+0}\right.$ weeks $),{ }^{19}$ with the exception of one at extreme preterm (25 weeks) and two at moderate preterm (34 weeks) gestational age. Perinatal mortality observed with uterine rupture occurred at a rate of $117 / 1000$ (95\% CI 60 to 203) compared with the perinatal mortality rate of $6.7 / 1000$ in the background population (RR $17.3,95 \%$ CI 9.6 to 31.0 ).

Seventy-four neonates survived (86\%), of whom 29 suffered from asphyxia (39\%). Twenty-four neonates needed intubation and ventilation $(33 \%)$, two neonates needed resuscitation at birth, five received cooling therapy (7\%) and one neonate required anticonvulsant drugs. Median gestational age at birth was 39 weeks (range 29-41 weeks) in the group of surviving neonates.

A higher risk of severe maternal outcome (hysterectomy, transfusion $>4$ units of $\mathrm{PC}$, admission to ICU) and severe neonatal outcome (asphyxia, intrapartum or neonatal death) was observed in women without previous CS than in women with a previous CS. A more in-depth analysis taking history of other uterine surgery into account reveals a further increased risk of severe maternal outcome in those women with other uterine surgery; however, numbers in this study are too small to permit firm conclusions (see online supplementary table S1).

\section{DISCUSSION}

The estimated prevalence $(3.6 / 10000$ deliveries $)$ of uterine rupture in Belgium, based on this study, is similar to that found in other Western countries. Compared with three national population-based studies that have used a similar approach: the Netherlands (LEMMoN-study), ${ }^{8}$ the UK (UKOSS) ${ }^{7}$ and the Nordic countries (Nordic Obstetric Surveillance Study, NOSS $){ }^{10}$ this prevalence stands roughly midway between the low rate of UKOSS (1.9/10 000) and the higher rates of NOSS (5.5/10 000) and LEMMoN (5.9/ $10000)$. Important is that UKOSS and NOSS have included only cases of complete rupture, while LEMMoN has no information on the anatomical details of the ruptures. The estimated prevalence of complete uterine ruptures in Belgium is 2.9/10 000 deliveries.

The strengths of this study are its methodology-collecting cases prospectively on a monthly basis-and its national design with excellent participation and response rates $(98.9 \%)$ from the Belgian maternity units. The small number of cases, intrinsic to rare but severe obstetric complications, warrants caution, however, in making strong inferences. Furthermore, we were unable to control for several variables not available from the background population through the Belgian perinatal registry. Finally, due to the study design and non-mandatory reporting of severe pregnancy complications, under-reporting may have biased our results to some extent, an issue we will address in a forthcoming study.

The majority of cases in this study fit the pattern of known risk factors for uterine rupture: scarring by a previous CS, being beyond 37 weeks of gestation, being in labour and being induced or augmented. Still, 17 cases had no previous CS, of which 8 ruptured before 37 weeks, and of which 2 were not in labour. Insight into circumstances and risk factors of rare cases of uterine rupture, namely occurring in the unscarred and/or preterm, and/or non-labouring uterus, can be improved by the study of a larger number of cases; the INOSS collaborative $^{5}$ may be the only route to achieve adequate numbers of these rare cases of uterine rupture.

This study confirms a higher risk of severe maternal and neonatal outcome when a rupture occurs in a uterus without previous CS, than among women with previous CS, as reported previously by the LEMMoN study, ${ }^{8}$ among others. ${ }^{3} 20$ This can be explained by the delay in diagnosis because of a lower suspicion of uterine rupture in an unscarred uterus and by the higher risk of massive haemorrhage in the more vascular, unscarred myometrium compared with in uterine scar tissue. A further increased risk of severe maternal outcome was observed when accounting for a history of other uterine surgery, though our observations are hypothesis-generating and need confirmation in larger study sets.

Evidence on the risk of uterine rupture following transabdominal or laparoscopic myomectomy remains inconclusive, because surgeons recommend a primary $\mathrm{CS}$ in a high number of these women. Based on the literature review, the risk of uterine rupture following myomectomy appears to be comparable to the risk after previous low transverse CS (around 0.5-0.7\%). ${ }^{21}$ Evidence-based guidelines on the mode of delivery following myomectomy, however, are not available. ${ }^{1}$ Further, this study includes three cases of fundal uterine rupture following salpingectomy, and two cases following hysteroscopic resection of a uterine septum. Evidence of uterine rupture following salpingectomy ${ }^{22} 23$ or following resection of a uterine septum ${ }^{24}$ is even more scarce, limited to case reports and series. In line with myomectomy, surgeons should evaluate and document the risk of uterine rupture based on intraoperative findings; next, OBs should be aware of this potential risk during antenatal care. Finally, to what extent can we assign the occurrence of a uterine rupture to an unnoted perforation during routine surgical procedures such as D\&C ( $\mathrm{n}=17$ in this study), diagnostic or simple operative hysteroscopy, or even the insertion of an intrauterine device? The exceptional case reports in the literature, in view of the frequency of these procedures, suggest that these are merely accidental findings. ${ }^{25}{ }^{26}$ Information on the prevalence of these routine surgical procedures in the background pregnant population, in relation to the prevalence of these procedures in a uterine rupture cohort, could provide a more accurate estimation of the relative risk. Linkage between national birth and medical registers, as is the case in the Nordic countries, ${ }^{27}$ may allow for studies of such magnitude. 
The overall CS rate in Belgium is slowly increasing and has just exceeded the landmark of $20 \%$. Although this rate is still acceptable ${ }^{13}$ the trend causes concern, awakened by recent reporting of the WHO stating that CS rates higher than $10 \%$ are not associated with reductions in maternal and newborn mortality rates. ${ }^{28}$ Belgium has no national guidelines for TOLAC specifically, hence Belgian OBs will turn to various guidelines (Royal College of Obstetricians and Gynaecologists (RCOG) ${ }^{1}$ American College of Obstetricians and Gynecologists (ACOG), ${ }^{11}$ Nederlandse Vereniging voor Obstetrie \& Gynaecologie (NVOG), ${ }^{29}$ French College of Gynecologists and Obstetricians (CNGOF) ${ }^{30}$ ) and literature to rely on in their daily practice. We observe a restrictive policy towards TOLAC in Belgium: in 20122013, 47.2\% of Belgian women with previous CS attempted a vaginal birth in their next pregnancy, with success in $69 \% .^{14-16}$ The estimated TOLAC rate in the Netherlands and the UK was $71.7 \%$ and $52.2 \%$, successful in $76 \%$ and $63.4 \%$, respectively. ${ }^{31} 32$

The percentage of women with TOLAC that was induced or augmented in this study is similar to that reported in the LEMMoN study (28\% induced, $25 \%$ augmented), ${ }^{8}$ yet higher than observed in the UKOSS study (14\% induced, $25 \%$ augmented). ${ }^{7}$ Prostaglandins were used in $27 \%$ (compared with $13 \%$ and $14 \%$ in LEMMoN and UKOSS, respectively). The reported doses and regimens were not according to guidelines in a small number of cases (intervals $<3 \mathrm{~h}$, maximum $24 \mathrm{~h}$ dose exceeded, misoprostol for induction of labour at 38 weeks). Thus, five cases of TOLAC were noted to be induced at 3839 weeks in the absence of a medical indication. These findings suggest that, despite an overall cautious attitude towards TOLAC in Belgium, a number of uterine rupture cases may have been avoidable as they were preceded by unneeded and unsafe procedures, inconsistent with current widely accepted guidelines. ${ }^{1} 11123033$

Accordingly, there seems to be scope for improvement in promoting a more liberal policy towards TOLAC in appropriate candidates in Belgium aiming to reduce the repeat and thus overall CS rate. Whether this will effectively result in a significant reduction of associated morbidity (rate of abnormally invasive placenta, massive obstetric haemorrhage, uterine rupture), may be the subject of future B.OSS surveillance.

\section{CONCLUSION}

On the basis of the findings in this study, we consider the need for nationally adopted guidelines on TOLAC in Belgium. These should be developed to improve the awareness of true uterine rupture risk, and thereby prevent unsafe procedures on the one hand, and promote safe TOLAC in appropriate candidates on the other, to enable reduction of the repeat and overall CS rate. There is need for further research on the true risk of uterine rupture following myomectomy and other uterine surgical procedures that similarly injure the myometrium, to develop evidence-based guidelines on the delivery mode in subsequent pregnancies. The INOSS enables the study of rare cases of uterine rupture, namely in the unscarred and/or preterm, and/ or non-labouring uterus and recurrent uterine rupture.

Acknowledgements This study would not have been possible without the voluntary participation of the Belgian maternity units: GZA Sint-Jozef, Mortsel; GZA Sint-Augustinus, Wilrijk; GZA Sint-Vincentius, Antwerpen; ZNA,

Sint-Erasmus, Borgerhout; ZNA, Jan Palfijn, Merksem; ZNA, Middelheim, Antwerpen; ASZ, campus Aalst; ASZ, campus Geraardsbergen; AZ Lokeren; Imelda Ziekenhuis, Bonheiden; Sint-Jozef, Bornem; AZ Klina, Brasschaat; AZ Sint-Jan, Brugge; AZ Sint-Lucas, Assebroek; Centre de Santé des Fagnes; Centre Hospitalier de l'Ardenne; Centre Hospitalier EpiCura, site Hornu; Centre Hospitalier de Mouscron; Centre Hospitalier du Bois de l'Abbaye et de Hesbay; Centre Hospitalier Peltzer, La Tourelle; CHC Saint-Vincent; CHC Saint-Joseph; CHC Sainte-Elisabeth; CHIREC, Clinique Sainte-Anne, Saint-Remi; CHIREC Braine-l'Alleud-Waterloo; CHR de la Citadelle; CHR de Namur; CHR du Val de Sambre; CHR Haute Senne-Le Tilleriau; CHR Mons Clinique Saint-Joseph; CHU Ambroise Paré; CHU Brugmann; CHU Charleroi, André Vésale; $\mathrm{CHU}$ Notre-Dame des Bruyères; CHU Saint-Pierre; CHU Tivoli; CHwapi-Site Notre-Dame; Clinique Edith Cavell; Clinique et Maternité Sainte Elisabeth; Clinique Notre dame de Grâce; Clinique Reine Astrid; Clinique Sainte-Piere; Cliniques de l'Europe, Saint-Michel; Cliniques de l'Europe, Sainte-Elisabeth; Cliniques du Sud Luxembourg; Cliniques Universitaires Saint-Luc; AZ Sint-Vincentius, Deinze; AZ Sint-Blasius, Dendermonde; AZ Monica, Deurne; AZ Diest; AZ Sint-Maarten, Duffel; AZ Alma, Eeklo; Dimpna Ziekenhuis, Geel; AZ Jan Palfijn, Gent; AZ Maria Middelares, Gent; AZ Sint-Lucas, Gent; GHDC asbl—Notre Dame; AZ Maria ziekenhuis, Halle; Jessaziekenhuis, Hasselt; AZ Sint Elisabeth, Herentals; CAZ Midden-Limburg, Heusden-Zolder; Hôpital Civil Marie Curie; Hôpital Erasme, Bruxelles; Hôpitaux Iris Sud-Site Ixelles; Jan Yperman ziekenhuis, leper; IFAC Hôpital Princesse Paola; INDC Entité Jolimontoise; Sint-Jozef ziekenhuis, Izegem; Kliniek Sint-Jan; Klinik Saint-Josef; AZ Zeno, campus Knokke-Heist; AZ Groeninge, Kortrijk; Heilig Hart ziekenhuis, Leuven; UZ Leuven; Heilig Hart ziekenhuis, Lier; AZ Sint-Jozef, Malle; AZ Sint-Maarten, Mechelen; AZ Delta, campus Menen; Heilig Hart ziekenhuis, Mol; Onze-Lieve-Vrouw ziekenhuis, campus Aalst; Onze-Lieve-Vrouw ziekenhuis, campus Asse; AZ Damiaan, campus Sint-Jozef, Oostende; AZ Sint-Jan, campus Oostende; Christine Dallequin AZ Oudenaarde; Mariaziekenhuis Noord-Limburg, Overpelt; AZ Heilige Familie, Reet AZ Delta, campus Brugsesteenweg, Roeselare; AZ Delta, campus Wilgenstraat, Roeselare; AZ Glorieux, Ronse; AZ Nikolaas, Sint-Niklaas; Sint-Trudo ziekenhuis, Sint-Truiden; Saint-Nikolaus Hospital; Sint-Andries ziekenhuis, Tielt; Heilig Hartziekenhuis, Tienen; AZ Vesalius, Tongeren;

Sint-Rembertziekenhuis, Torhout; AZ Turnhout; UZ Antwerpen; UZ Brussel; AZ Sint-Augustinus, Veurne; AZ Jan Portaels, Vilvoorde; Onze-Lieve-Vrouw van Lourdes ziekenhuis, Waregem; Ziekenhuis Oost-Limburg, campus Sint-Jan Genk; AZ Sint-Elisabeth, Zottegem. The authors would like to thank Fatima Bercha, Marine Guisset, Ann Langedock, Marlies Maly, Emilie Vandevoorde and Iris Janssens for their contribution in collecting and processing the data.

Contributors $\mathrm{MH}$ and YE conceived the project. MH, YE, GV, MDB and VVL designed the study. GV, MDB, VVL and MH collected the data. GV, MDB, KR and $H V$ analysed the data. GV and HV wrote the first draft of the manuscript. $\mathrm{MDB}, \mathrm{KR}$ and $\mathrm{HV}$ contributed to the writing of the manuscript. MDB, VVL, $\mathrm{KR}, \mathrm{HV}, \mathrm{MH}$ and YE critically revised the manuscript. GV, MDB, VVL, KR, MH, $\mathrm{YE}$ and $\mathrm{HV}$ approved the final version.

Funding The study was funded by the College for Mother and Newborn, a consultative body of the Federal Public Service of Health in Belgium. GV was funded by the Research Foundation Flanders (FWO) (grant number FW014/ $\mathrm{KDB} / 003)$.

\section{Competing interests None declared.}

Ethics approval The collection of patient information by B.OSS has been approved by the Medical Ethics Committee of the Ghent University Hospital (EC UZG 2012/734; B670201215359) and by the Medical Ethics Committee 
of the University Hospital Erasme, Brussels (EC ULB 2012/111; B406201213660)

Data sharing statement No additional data are available.

Open Access This is an Open Access article distributed in accordance with the Creative Commons Attribution Non Commercial (CC BY-NC 4.0) license, which permits others to distribute, remix, adapt, build upon this work noncommercially, and license their derivative works on different terms, provided the original work is properly cited and the use is non-commercial. See: http:// creativecommons.org/licenses/by-nc/4.0/

\section{REFERENCES}

1. Royal College of Obstetricians and Gynaecologists (RCOG). Birth after previous caesarean birth. Green-top guideline no. 45. 2015. http://www.rcog.org.uk/globalassets/documents/guidelines/gtg_45. pdf (accessed 21 Oct 2015).

2. Landon MB, Hauth JC, Leveno $\mathrm{KJ}$, et al. Maternal and perinatal outcomes associated with a trial of labor after prior cesarean delivery. N Engl J Med 2004;351:2581-9.

3. Hofmeyr GJ, Say L, Gülmezoglu AM. WHO systematic review of maternal mortality and morbidity: the prevalence of uterine rupture. BJOG 2005;112:1221-8.

4. Knight M, Kurinczuk JJ, Tuffnell D, et al. The UK Obstetric Surveillance System for rare disorders of pregnancy. BJOG 2005;112:263-5.

5. Knight M, INOSS. The International Network of Obstetric Survey Systems (INOSS): benefits of multi-country studies of severe and uncommon maternal morbidities. Acta Obstet Gynecol Scand 2014;93:127-31.

6. Kaczmarczyk M, Sparén $P$, Terry $P$, et al. Risk factors for uterine rupture and neonatal consequences of uterine rupture: $a$ population-based study of successive pregnancies in Sweden. BJOG 2007;114:1208-14.

7. Fitzpatrick KE, Kurinczuk JJ, Alfirevic Z, et al. Uterine rupture by intended mode of delivery in the UK: a national case-control study. PLoS Med 2012;9:e1001184.

8. Zwart JJ, Richters JM, Ory F, et al. Uterine rupture in The Netherlands: a nationwide population-based cohort study. BJOG 2009;116:1069-78.

9. Al-Zirqi I, Stray-Pedersen B, Forsén L, et al. Uterine rupture: trends over 40 years. BJOG 2016;123:780-7.

10. Colmorn LB, Petersen KB, Jakobsson M, et al. The Nordic Obstetric Surveillance Study: a study of complete uterine rupture, abnormally invasive placenta, peripartum hysterectomy and severe blood loss at delivery. Acta Obstet Gynecol Scand 2015;94:734-44.

11. American College of Obstetricians and Gynecologists. ACOG Practice Bulletin no. 115: vaginal birth after previous cesarean delivery. Obstet Gynaecol 2010;116:450-63.

12. Society of Obstetricians and Gynaecologists of Canada. SOGC Clinical Practice Guidelines. Guidelines for vaginal birth after previous caesarean birth. Number 155 (Replaces guideline Number 147). Int J Gynaecol Obstet 2005;89:319-31.

13. EUROPEAN PERINATAL HEALTH REPORT. Health and care of pregnant women and babies in Europe in 2010. http://www. europeristat.com/images/doc/EPHR2010_w_disclaimer.pdf (accessed 21 Oct 2015).

14. Cammu H, Martens E, Martens G, et al. Perinatale Activiteiten in Vlaanderen 2013. Brussels: SPE, 2014. http://www. zorg-en-gezondheid.be/uploadedFiles/NLsite_v2/Cijfers/Cijfers over_geboorte_en_bevalling/SPE_jaarrapport\%202013.pdf (accessed 21 Oct 2015).
15. Van Leeuw V, Leroy $\mathrm{CH}$, Englert Y. Données périnatales en Région bruxelloise-Année 2013. Centre d'Épidémiologie Périnatale, 2015. http://www.cepip.be/pdf/rapport_CEPIP_Bxl2013_tma-FR.pdf (accessed 21 Oct 2015)

16. Leroy $\mathrm{CH}$, Van Leeuw V, Englert Y. Données périnatales en Wallonie-Année 2013. Centre d'Épidémiologie Périnatale, 2015. http://www.cepip.be/pdf/rapport_CEPIP_wallonie2013_tmab.pdf (accessed 21 Oct 2015).

17. No authors listed]. Executive summary: neonatal encephalopathy and neurologic Outcome, second Edition. Report of the American College of Obstetricians and Gynecologists' Task force on Neonatal Encephalopathy. Obstet Gynecol 2014;123:896-901.

18. Bishop EH. Pelvic scoring for elective induction. J Obstet Gynecol 1964;24:266-8.

19. No authors listed]. ACOG Committee Opinion No. 579: definition of term pregnancy. Obstet Gynecol 2013;122:1139-40.

20. Walsh CA, Baxi LV. Rupture of the primigravid uterus: a review of the literature. Obstet Gynecol Surv 2007;62:327-34.

21. Landon MB, Lynch CD. Optimal timing and mode of delivery after cesarean with previous classical incision of myomectomy: a review of the data. Semin Perinatol 2011;35:257-61.

22. Nishijima Y, Suzuki T, Kashiwagi $\mathrm{H}$, et al. Uterine rupture at 26 weeks of pregnancy following laparoscopic salpingectomy with resection of interstitial portion: a case report. Tokai J Exp Clin Med 2014;39:167-71.

23. Inovay J, Marton T, Urbancsek J, et al. Spontaneous bilateral cornual uterine dehiscence early in the second trimester after bilateral laparoscopic salpingectomy and in-vitro fertilization: a case report. Hum Reprod 1999;14:2471-3.

24. Sentilhes L, Sergent F, Roman H, et al. Late complications of operative hysteroscopy: predicting patients at risk of uterine rupture during subsequent pregnancy. Eur J Obstet Gynecol Reprod Bio 2005;120:134-8.

25. Zwart JJ, Van Huisseling $\mathrm{HC}$, Schuttevaer $\mathrm{HM}$, et al. Nearly fata uterine rupture during manual removal of the placenta: a case report. J Reprod Med 2007;52:974-6.

26. Misra M, Roychowdhury R, Sarkar NC, et al. The spontaneous prelabour rupture of an unscarred uterus at 34 weeks of pregnancy. J Clin Diagn Res 2013;7:548-9.

27. Langhoff-Roos J, Krebs L, Klungsøyr K, et al. The Nordic medical birth registers-a potential goldmine for clinical research. Acta Abstet Gynecol Scand 2014;93:132-7.

28. Ye J, Zhang J, Mikolajczyk R, et al. Association between rates of caesarean section and maternal and neonatal mortality in the $21 \mathrm{st}$ century: a worldwide population-based ecological study with longitudinal data. BJOG 2015.

29. Nederlandse Vereniging voor Obstetrie \& Gynaecologie. Richtlijnen Zwangerschap en bevalling na een voorgaande sectio caesarea. Goedkeuring 2010-06-04. http://nvog-documenten.nl/index.php? pagina=/richtlijn/pagina.php\&fSelectTG_62=75\&fSelectedSub= 62\&fSelectedParent $=75$ (accessed 21 Oct 2015).

30. Sentilhes L, Vayssière $C$, Beucher $G$, et al. Delivery for women with a previous cesarean: guidelines for clinical practice from the French College of Gynecologists and Obstetricians (CNGOF). Eur J Obstet Gynecol Reprod Biol 2013;170:25-32.

31. Kwee A, Bots ML, Visser GH, et al. Obstetric management and outcome of pregnancy in women with a history of caesarean section in the Netherlands. Eur J Obstet Gynaecol Reprod Biol 2007;132:171-6.

32. Knight HE, Gurol-Urganci I, van der Meulen JH, et al. Vaginal birth after caesarean section: a cohort study investigating factors associated with its uptake and success. BJOG 2014;121:183-93.

33. Jozwiak M, Dodd JM. Methods of term labour induction for women with a previous caesarean section. Cochrane Database Syst Rev 2013;3:CD009792. 